\title{
Efeitos do ensino explícito da gramática no desenvolvimento de diferentes tipos de propriedades em L $2^{1}$
}

\author{
Joana Teixeira \\ NOVA FCSH / CLUNL
}

\begin{abstract}
:
The present study investigates the effects of explicit grammar teaching on the acquisition of a core syntactic property (the ungrammaticality of free inversion) and a syntax-discourse property (the unacceptability of locative inversion with informationally heavy verbs) by advanced and upper intermediate Portuguese learners of English. The study followed a pre-test/post-test design. Its results reveal that, at an upper intermediate level, explicit teaching did not have any effects on learners' performance, regardless of the type of property. At an advanced level, in contrast, the teaching intervention resulted in gains in all cases. However, these gains were only maintained beyond the immediate teaching period when the target property was strictly syntactic. These findings indicate that the effectiveness of instruction depends on the stage of development at which learners are and on the type of target property. The pedagogical implications of the findings are discussed in detail.
\end{abstract}

Keywords: L2 acquisition, explicit grammar teaching, syntax, syntax-discourse

Palavras-chave: aquisição de L2, ensino explícito da gramática, sintaxe, sintaxe-discurso

\section{Introdução}

A investigação desenvolvida no domínio de aquisição de língua segunda (L2) tem mostrado, de forma consistente, que o ensino explícito da gramática melhora o conhecimento explícito dos aprendentes de L2 (e.g., Goo, Granena, Yilmaz, \& Novella, 2015; Norris \& Ortega, 2000; Spada \& Tomita, 2010; Umeda, Snape, Yusa, \& Wiltshier, 2019), mas tem produzido resultados contraditórios quanto à seguinte questão-chave, que é relevante não só para este domínio científico, mas também para a didática de L2: o ensino explícito da gramática pode promover a aquisição de conhecimento implícito em L2 (i.e., conhecimento inconsciente disponível para uso automático em compreensão e produção espontâneas)? Por um lado, há muitos trabalhos que mostram que o ensino explícito não resulta em ganhos em termos de conhecimento implícito (e.g., Gil, Marsden, \& Whong, 2013a, 2013b; Lopez, 2019; Macaro \& Masterman, 2006; Umeda, Snape, Yusa, \& Wiltshier, 2019; White, 1991). Por outro, há alguma evidência de que este tipo de ensino pode desencadear aquisição de tal conhecimento (e.g., Akakura, 2012; Ellis, 2002a; Slabakova, 2002).

Diversos fatores têm sido apontados como potenciais variáveis moderadoras da eficácia do ensino explícito da gramática em L2 (para uma visão panorâmica, cf. de Graaff \& Housen, 2009). Entre eles destacamse o timing do ensino e o tipo de propriedade alvo. Relativamente ao primeiro fator, Pienemann (1984, 1989, 2005) propõe que o ensino explícito sobre uma propriedade $\mathrm{P}$ apenas promove aquisição em L2 quando o aprendente se encontra num estádio de desenvolvimento imediatamente anterior ao estádio em que $\mathrm{P}$ é adquirida. No entanto, a investigação sobre esta hipótese, conhecida como Hipótese de Ensinabilidade (Teachability Hypothesis), não é conclusiva: enquanto muitos estudos (e.g., Mackey \& Philp, 1998; Pienemann,

\footnotetext{
${ }^{1}$ A investigação conducente a este artigo foi desenvolvida no âmbito do projeto de doutoramento "L2 acquisition at the interfaces: Subjectverb inversion in L2 English and its pedagogical implications", financiado pela Fundação para a Ciência e a Tecnologia através de uma Bolsa de Doutoramento individual (ref. ${ }^{a}$ PD/BD/52263/2013). Agradeço aos dois avaliadores anónimos da Revista da APL pelos seus comentários e a Ana Madeira pelas úteis sugestões que me deu nas diferentes fases de desenvolvimento deste estudo.
} 
1984, 1989) confirmam as predições desta hipótese, outros sugerem que o ensino explícito resulta em aquisição, mesmo quando a propriedade alvo está mais do que um estádio acima daquele em que o aprendente se encontra (e.g., Spada \& Lightbown, 1999). Relativamente ao fator "tipo de propriedade alvo", vários autores têm levantado a hipótese de que a eficácia do ensino explícito poderá variar em função da complexidade do fenómeno linguístico a ser aprendido (e.g., DeKeyser, 1995; Ellis, 2002a). Todavia, também neste caso os estudos prévios apresentam resultados contraditórios. Alguns sugerem que o ensino explícito é mais eficaz quando tem como foco propriedades simples da L2 (e.g., DeKeyser, 1995; Robinson, 1996). Outros indicam que o ensino explícito é mais eficaz quando as propriedades alvo são complexas (e.g., de Graaff, 1997; Housen, Pierrard, \& Van Daele, 2005). Por seu lado, uma meta-análise de Spada e Tomita (2010) indica que o ensino explícito resulta em ganhos quer quando as propriedades alvo são simples, quer quando são complexas, colocando, assim, em causa a hipótese de que o tipo de propriedade alvo influencia a eficácia do ensino.

Estas contradições quanto ao papel da propriedade alvo podem resultar de dois problemas na investigação que tem sido feita sobre o tema. O primeiro é a diversidade de definições de complexidade linguística que tem sido usada nos estudos (ver de Graaf \& Housen, 2009). O segundo é a inadequação de muitas destas definições, que não têm em conta os resultados da investigação sobre aquisição da gramática em L2. A título de exemplo, consideremos a meta-análise de Spada e Tomita (2010). As autoras definiram complexidade linguística em termos do número de derivações envolvidas para se chegar a uma dada forma linguística. Com base nesta medida de complexidade, classificaram os artigos como propriedades simples. Contudo, estudos no âmbito da Gramática Generativa sobre aquisição de L2 têm mostrado, de forma consistente, que os artigos não são fáceis de adquirir (e.g., Ionin, Ko, \& Wexler, 2004; Ionin, Montrul, \& Santos, 2011). A medida de complexidade linguística usada não é, portanto, fiável, o que põe em causa os resultados da meta-análise.

Segundo Whong, Gil e Marsden (2014), a solução para estes problemas de definição poderá ser encontrada, precisamente, na investigação generativa sobre aquisição de L2. Muitos dos trabalhos desenvolvidos nesta área têm mostrado que os domínios específicos envolvidos numa dada propriedade linguística influenciam o grau de dificuldade da sua aquisição (e.g., Slabakova, 2008; Sorace, 2011). Há, por exemplo, muita evidência de que propriedades estritamente sintáticas tendem a ser mais fáceis de adquirir do que propriedades na interface sintaxe-discurso, que, frequentemente, causam problemas até a falantes quasenativos de L2 (i.e., falantes que se encontram no nível mais avançado que pode ser alcançado numa L2) (Sorace, 2011, 2016). Estes resultados suscitam a seguinte questão: será que a complexidade do(s) domínio(s) linguístico(s) envolvido(s) na propriedade alvo influencia a eficácia do ensino explícito da gramática?

Com vista a investigar esta questão, que permanece por explorar, e examinar o impacto do timing na eficácia do ensino explícito da gramática, o presente trabalho estuda o efeito do ensino explícito na aquisição de duas propriedades linguísticas por aprendentes portugueses de inglês L2 nos níveis B2 (intermédio alto) e C1 (avançado): uma propriedade sintática - a agramaticalidade de inversão livre em inglês - e uma propriedade sintático-discursiva - a inaceitabilidade de inversão locativa em inglês com verbos que não sejam informacionalmente leves (i.e., verbos que introduzem informação além da presença/existência do sujeito - cf. Levin \& Rappaport Hovav, 1995: 215-278). Estes fenómenos foram selecionados por serem semelhantes em aspetos fundamentais: (i) envolvem o mesmo tipo de fenómeno gramatical - inversão sujeito-verbo; (ii) envolvem a mesma tarefa de aprendizagem - eliminar uma opção da língua materna (L1) impossível na L2 e manter uma opção partilhada pela L1 e pela L2 (cf. secção 2.1); (iii) geram dificuldades aos aprendentes portugueses de inglês até estádios tardios (cf. secção 2.2); e (iv) tipicamente, não são ensinados explicitamente nas aulas de inglês.

O presente artigo está estruturado da seguinte forma: a secção 2 descreve como o inglês e o português europeu (PE) se comportam em relação aos fenómenos linguísticos que serão alvo de intervenção didática neste trabalho - a inversão livre e a inversão locativa - e resume os principais resultados de estudos prévios sobre a sua aquisição em inglês L2. Na secção 3, apresentamos as questões de investigação e a metodologia do presente 
estudo. Os seus resultados são descritos na secção 4 e discutidos na secção 5. A secção 6 analisa as potenciais implicações didáticas dos resultados obtidos. Por fim, as principais conclusões do artigo são apresentadas na secção 7 .

\section{Inversão livre e inversão locativa}

\subsection{Nas gramáticas dos falantes nativos de inglês e de $P E$}

O inglês e o PE têm a mesma ordem básica de palavras: S(ujeito) - V(erbo) - O(bjeto). No entanto, esta ordem não é igualmente flexível nas duas línguas. Enquanto o inglês apenas admite inversão sujeito-verbo (i.e., ordens $\mathrm{V}_{\text {lexical }} \mathrm{S}$ ) num número restrito de construções como a de inversão locativa (1), o PE impõe poucas restrições à ocorrência desta inversão. Em PE, a inversão sujeito-verbo é possível com todos os tipos de verbos e sem nenhum elemento realizado em posição canónica de sujeito, como em (2). Por este motivo, a inversão é considerada "livre" em PE.

(1) On the horizon appeared a large ship. (Levin, 1993: 258)

(2) a. *Appeared the ship.

b. Apareceu o navio.

A inversão livre está, porém, sujeita a condições discursivas. Em frases declarativas simples, é admitida quando o sujeito é focalizado contrastivamente (3), em contextos de foco informacional estreito (i.e., contextos em que apenas o sujeito é foco), como (4), e contextos de foco informacional largo (i.e., contextos em que toda a frase é foco), como (5) (e.g., Costa, 2004; Lobo \& Martins, 2017; Sheehan, 2010). O presente trabalho debruça-se sobre estes dois últimos contextos.

(3) Hoje comprou o João o pão, amanhã compro eu. ${ }^{2}$
a. A: Quem chegou/gritou?
B: $\quad$ i. Chegou/gritou a Ana. *Arrived/screamed Ana.
b. A: Quem partiu o copo?
B: $\quad$ i. Partiu(-o) a Ana. $\quad$ Broke it Ana.

(5) A: O que aconteceu?

B: $\quad$ i. Chegou/\#gritou a Ana. *Arrived/screamed Ana.

ii. A Ana chegou/gritou. Ana arrived/screamed.

Em contextos de foco estreito, a ordem VS é possível com todos os tipos de verbos e é claramente preferida à ordem SV, embora ambas sejam gramaticais (4). Já em contexto de foco largo, quer a ordem VS, quer a ordem SV são discursivamente adequadas. Contudo, neste caso, a ordem VS só é admissível com um grupo restrito de verbos intransitivos a que Pinto (1997) chama "verbos de inversão" (e.g., chegar e telefonar), cf. (5). Como mostram os exemplos (6), ao contrário do PE, o inglês permite apenas ordens SV nos contextos de foco estreito e de foco largo.

\footnotetext{
${ }^{2}$ Exemplo fornecido por um avaliador anónimo, a quem agradeço.
} 
(6) A: Who arrived? / What happened?

B: $\quad$ i. *Arrived Ana.

ii. Ana arrived.

A inversão livre não é gramatical em inglês, porque, diferentemente do PE, esta é uma língua de sujeito obrigatório e, consequentemente, exige que o Princípio de Projeção Alargada (PPA) - i.e., o princípio universal que determina que a posição canónica de sujeito deve ser preenchida em todas as frases (Chomsky, 1981) - seja satisfeito por material foneticamente realizado. Devido a este facto sintático, o inglês só permite que o sujeito não se mova para a posição canónica de sujeito quando há, na frase, algum outro constituinte foneticamente realizado que satisfaça o PPA, como, por exemplo, um SP locativo como on the horizon em (1). É por isso que o inglês não admite inversão livre (6), mas permite inversão locativa (1).

Em inglês, a inversão locativa tem a função discursiva de apresentar um referente não pressuposto num cenário espácio-temporal pressuposto (Bresnan, 1994; Ward, Birner, \& Huddleston, 2002). Por este motivo, apenas é discursivamente adequada quando o sujeito é (parte do) foco (e.g., Bresnan, 1994; Culicover \& Winkler, 2008) e o constituinte pré-verbal é um tópico cénico, i.e., um constituinte pressuposto que define uma localização espácio-temporal (Teixeira, 2016), tal como ilustrado em (7).

(7) a. They have a great big tank in the kitchen, and [in the tank are sitting a whole bunch of pots].

b. They have a whole bunch of pots in the kitchen, and \#[in a great big tank are sitting all of the pots]. (Ward, Birner, \& Huddleston, 2002: 1386)

Vários estudos (e.g., Holler \& Hartmann, 2012; Levin \& Rappaport Hovav, 1995; Ward et al., 2002) têm mostrado que, contrariamente ao que era tradicionalmente assumido na literatura (e.g., Bresnan, 1994), a aceitação de um verbo em estruturas de inversão locativa não depende do seu estatuto inacusativo. Como Levin e Rappaport Hovav (1995: 228) defendem, "it is the discourse function of the [locative inversion] construction that restricts the set of verbs in it". Para serem admitidos em estruturas de inversão locativa, os verbos têm de ser compatíveis com a função apresentacional deste tipo de inversão. Na prática, isto significa que os verbos têm de ser "informacionalmente leves", i.e., devem acrescentar pouca ou nenhuma informação além da existência/surgimento do sujeito (cf. Levin e Rappaport Hovav, 1995).

Esta condição discursiva é satisfeita por verbos inacusativos de existência e aparecimento, como appear ('aparecer') em (1) e come ('vir') em (8), e verbos inergativos redundantes, i.e., inergativos que não expressam uma atividade prototípica do referente do sujeito e são, consequentemente, reduzidos a uma interpretação apresentacional/existencial, como é o caso dos verbos wave ('esvoaçar') e sing ('cantar') em (9) (Levin, 1993; Levin \& Rappaport Hovav, 1995).

(8) Out of the house came a tiny old lady. (Levin \& Rappaport Hovav, 1995: 241)

(9) a. From the flagpole waved a tattered banner. (Levin \& Rappaport Hovav, 1995: 259)

b. In the church sang a choir. (Levin, 1993: 93)

Os verbos que são incompatíveis com a função apresentacional da inversão locativa não são admitidos nesta construção em inglês. Este é o caso de verbos inergativos não redundantes, como os verbos wave ('acenar') e shop ('comprar') em (10), e de verbos inacusativos de mudança de estado, como break ('partir') e melt ('derreter') em (11). Os primeiros introduzem informação que vai além da mera asserção da existência/aparecimento do sujeito (Levin e Rappaport Hovav, 1995). Os últimos, por seu lado, são tipicamente incompatíveis com uma função apresentacional, pois aquilo que se derrete ou parte desaparece e, portanto, não pode ser introduzido no cenário definido pelo constituinte anteposto (Holler \& Hartmann, 2012). Os verbos inacusativos de mudança de estado só são admitidos em estruturas de inversão locativa quando perdem o seu sentido de mudança de estado e denotam existência/aparecimento (Levin, 1993; Levin e Rappaport Hovav, 
1995), como é o caso de break em (12a), ou quando coocorrem com um sujeito que se refere a uma entidade cuja existência é caracterizada pela ação expressa pelo verbo, como em (12b). Aqui o verbo burn ('arder') é informacionalmente leve, porque é previsível em relação ao sujeito (as velas são feitas para arder). Crucialmente, quando o verbo e o sujeito não são mutuamente previsíveis, o inglês não permite inversão locativa com o verbo burn, como o exemplo (12c) mostra.

(10) a. *From the roof waved a bearded student. (Levin \& Rappaport Hovav, 1995: 259)

b. *At the supermarket on the Main St. shop local residents. (Levin \& Rappaport Hovav, 1995: 222)

(11) a. *On the streets of Chicago melted a lot of snow.

b. *On the top floor of the skyscrapers broke many windows.

(Levin \& Rappaport Hovav, 1995: 224)

(12) a. Then broke the war.

b. On my desk burnt a thick candle.

c. *In London burnt a train station.

(Levin \& Rappaport Hovav, 1995: 234-235; exceto (12c))

Podemos, assim, concluir que, em inglês, a única subclasse de verbos que é sempre admitida em inversão locativa é precisamente a que é intrinsecamente leve de um ponto de vista informacional: a subclasse de verbos inacusativos de existência e aparecimento. Os restantes verbos intransitivos são rejeitados ou admitidos consoante sejam informacionalmente pesados ou leves no contexto particular em que estão encaixados (cf. os exemplos acima com o verbo inergativo wave e com os inacusativos de mudança de estado break e burn).

Ao contrário do inglês, o PE admite ordens Loc VS com todos os tipos de verbos (13), incluindo os que são informacionalmente pesados, como verbos de mudança de estado (13b) e inergativos não redundantes (13d) (Pereira, 1998).

(13) a. Inacusativo de existência e aparecimento: No horizonte apareceu um grande navio. / On the horizon appeared a large ship.

b. Inacusativo de mudança de estado: Nas ruas de Chicago derreteu muita neve. / *On the streets of Chicago melted a lot of snow.

c. Inergativo redundante: Na igreja cantou um coro. / In the church sang a choir.

d. Inacusativo não redundante: Nos serviços governamentais reclamam (diariamente) muitas pessoas descontentes. / *In government offices complain (everyday) many disgruntled people. (Levin and Rappaport Hovav, 1995: 222)

Note-se que, ao contrário do que acontece em inglês, em português, estruturas de inversão como as apresentadas em (13) não dependem da presença de um elemento loco-temporal em posição inicial para serem admitidas, tal como mostram os exemplos (14). Por isso, embora vários autores descrevam estas estruturas do português como inversão locativa (e.g., Pereira, 1998), pode considerar-se que são, na verdade, estruturas de inversão livre com um tópico cénico em posição inicial.

(14) a. Apareceu um grande navio no horizonte. / *Appeared a large ship on the horizon.

b. Cantou um coro na igreja. / *Sang a choir in the church.

Em síntese, enquanto o PE permite ordens SV e VS em contextos de foco estreito e largo e estruturas Loc VS com verbos informacionalmente leves e pesados, o inglês só admite ordens SV e também só permite verbos informacionalmente leves em inversão locativa. A tarefa de aprendizagem dos aprendentes portugueses de inglês é, assim, idêntica na aquisição de inversão locativa e dos padrões de colocação do sujeito em contextos 
de foco estreito e largo: eliminar uma opção da L1 que é impossível na L2, mantendo, ao mesmo tempo, uma opção partilhada pelas duas línguas. As tarefas de aprendizagem para os dois fenómenos considerados neste estudo diferem, contudo, em relação aos domínios linguísticos envolvidos. Por um lado, a eliminação de inversão livre requer saber que o PPA deve ser satisfeito por material foneticamente realizado em inglês, o que é uma propriedade estritamente sintática. Por outro lado, a eliminação da possibilidade de ordens Loc VS com verbos informacionalmente pesados depende da aquisição da condição discursiva a que os verbos estão sujeitos na inversão locativa do inglês, envolvendo, portanto, a interface sintaxe-discurso. ${ }^{3}$

\subsection{Em inglês $L 2$}

Nos últimos anos, a investigação generativa em aquisição de L2 tem mostrado que os aprendentes de inglês que têm como L1 o PE ou línguas tipologicamente semelhantes têm dificuldade em eliminar a possibilidade de inversão livre das suas interlínguas e tendem a exibir dificuldades em relação à condição discursiva a que os verbos estão sujeitos em inversão locativa até estádios muito tardios de aquisição.

Consideremos o caso da inversão livre em inglês L2. Os poucos estudos existentes sobre este fenómeno revelam que os falantes nativos de línguas de sujeito nulo como o PE e o Grego aceitam inversão livre em inglês até um nível avançado de proficiência (Prentza \& Tsimpli, 2013; Teixeira, 2018). Tipicamente, só eliminam completamente esta inversão das suas gramáticas mentais no nível quase nativo (Teixeira, 2018).

Enquanto a agramaticalidade de inversão livre é completamente adquirível, a distribuição dos verbos em estruturas de inversão locativa parece ser uma área de divergência permanente em inglês L2. Num estudo com falantes avançados e quase nativos de inglês L2 que tinham como L1 o PE e o francês (língua semelhante ao inglês nos aspetos relevantes), Teixeira $(2017,2018,2020)$ verificou que todos os grupos de falantes de L2 aceitavam inversão locativa não só com verbos informacionalmente leves (inacusativos de existência e aparecimento e inergativos redundantes), mas também com verbos informacionalmente pesados (inacusativos de mudança de estado e inergativos não redundantes). A possibilidade de inversão livre foi também testada com os mesmos grupos de falantes e só um deles aceitava este tipo de inversão em inglês: o grupo de falantes avançados com PE como L1. Parece, assim, que eliminar a possibilidade de inversão locativa com verbos informacionalmente pesados é mais difícil para os aprendentes de inglês do que eliminar inversão livre.

Em conjunto, estes resultados apoiam uma hipótese muito influente em aquisição de L2, a Hipótese de Interface (Sorace, 2011; Sorace \& Filiaci, 2006). De acordo com esta hipótese, as propriedades que são estritamente sintáticas são completamente adquiríveis numa L2, enquanto as que envolvem a interface entre sintaxe e domínios externos à gramática, como discurso, são vulneráveis a opcionalidade (i.e., alternância entre formas alvo e não alvo) permanente, independentemente das combinações L1-L2.

Em síntese, as propriedades que serão alvo de intervenção didática no presente estudo são particularmente difíceis de adquirir em PE L1 - inglês L2. Embora as duas construções de inversão consideradas envolvam o mesmo tipo de tarefa de aprendizagem (cf. secção 2.1), a inversão locativa é mais problemática para os aprendentes do que a inversão livre, possivelmente pelo facto de envolver uma das áreas mais vulneráveis à opcionalidade permanente em L2: a interface sintaxe-discurso. ${ }^{4}$

\footnotetext{
${ }^{3}$ Um avaliador anónimo sugere que a eliminação da possibilidade de ordens Loc VS com verbos informacionalmente pesados também poderá depender da eliminação da possibilidade de inversão livre. No entanto, esta não é uma condição suficiente e pode não ser necessária. Se o aprendente dominar a restrição discursiva a que os verbos estão sujeitos nas estruturas Loc VS do inglês, poderá rejeitar estas estruturas com verbos informacionalmente pesados, mesmo que ainda admita inversão livre.

${ }^{4}$ Como a (a)gramaticalidade de inversão livre e de inversão locativa depende do PPA e a inversão locativa está adicionalmente sujeita a uma condição discursiva, poderia argumentar-se que a inversão locativa causa mais problemas do que a inversão livre por envolver duas restrições. No entanto, os resultados da investigação existente sobre inversão locativa não apoiam esta hipótese. Estudos de Lozano e Mendikoetxea (2010) e Teixeira (2018) mostram que os aprendentes espanhóis e portugueses de inglês não têm dificuldades em aprender que os locativos podem satisfazer o PPA e que a ordem Loc VS é admitida em inglês. O que é problemático para eles é dominar a distribuição dos verbos nesta estrutura de inversão (cf. também os resultados dos pré-testes na secção 4.2). Portanto, é a restrição discursiva que se
} 


\section{O presente estudo: questões e metodologia}

\subsection{Questões de investigação}

À luz do atual estado da arte, formulámos as seguintes questões de investigação:

i. O ensino explícito ajuda os aprendentes de inglês L2 a ultrapassar as suas dificuldades em relação a um fenómeno estritamente sintático como a agramaticalidade de inversão livre?

ii. O ensino explícito ajuda os aprendentes de inglês L2 a ultrapassar as suas dificuldades em relação a um fenómeno linguístico que envolve a interface sintaxe-discurso, como a inaceitabilidade de inversão locativa com verbos informacionalmente pesados?

iii. Será que a eficácia do ensino explícito varia de acordo com o tipo de propriedade alvo? Se sim, como?

iv. Será que eficácia do ensino explícito varia em função do estádio de aquisição em que os aprendentes de L2 se encontram? Se sim, como?

\subsection{Desenho do estudo}

Para investigar estas questões, realizámos um estudo exploratório com aprendentes portugueses de inglês L2. Este estudo seguiu um desenho pré-teste/pós-teste e envolveu uma intervenção didática de duas semanas e meia. Durante a intervenção, um grupo de aprendentes, o grupo experimental, recebeu ensino explícito sobre os tipos de verbos (in)compatíveis com inversão locativa e sobre a (im)possibilidade de ordens SV/VS em contextos de foco estreito e de foco largo em inglês. Este grupo foi testado antes, imediatamente depois, e cinco semanas depois da intervenção didática (cf. Tabela 1).

Os dois pós-testes tiveram como propósito aferir se a intervenção resultou em ganhos de médio e/ou de curto prazo. Estes dados são essenciais para podermos determinar se o ensino explícito afetou apenas o conhecimento explícito dos aprendentes ou se desencadeou a aquisição de conhecimento implícito, pois uma das diferenças cruciais entre estes dois tipos de conhecimento linguístico é a sua durabilidade: o conhecimento implícito é duradouro, enquanto o conhecimento explícito da gramática, como outros factos declarativos, é esquecido facil e rapidamente (Ellis et al., 2009).

Além do grupo experimental, em todas as ocasiões de teste, foi também testado um grupo de controlo composto por aprendentes com um perfil sociolinguístico semelhante, mas que não participaram na intervenção didática. Foi ainda incluído neste estudo um grupo de falantes nativos de inglês, a fim de se poder determinar o grau de convergência/divergência dos aprendentes em relação à língua alvo. Este grupo apenas realizou o préteste.

aplica à inversão locativa que gera dificuldades aos aprendentes e não o facto de a aceitabilidade de inversão locativa depender simultaneamente desta restrição e do PPA. 


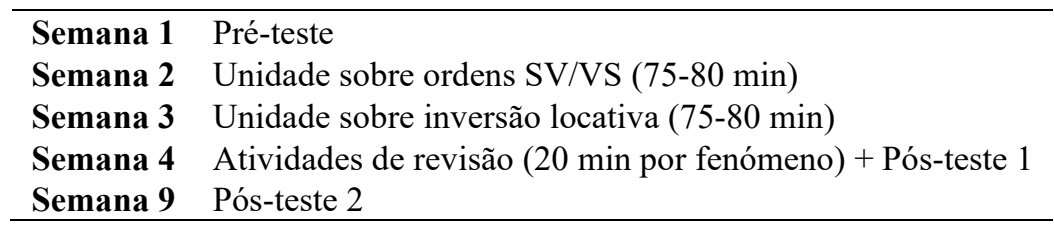

Tabela 1: Calendário do estudo

\subsection{Participantes}

Participaram no estudo 20 falantes nativos de PE, com idades compreendidas entre os 18 e os 28 anos, que frequentavam um curso de inglês B2.2 numa universidade portuguesa. Os participantes foram selecionados com base nos seus resultados no pré-teste, que será descrito na seção 3.5. Apenas foram incluídos os aprendentes que apresentavam problemas em relação às duas propriedades alvo deste estudo. Um teste de colocação em nível, o Quick Placement Test (University of Cambridge Local Examination Syndicate \& Oxford University, 2001), determinou que, dos 20 participantes selecionados, 10 tinham o nível B2 (= intermédio alto) e 10 estavam já no nível C1 (= avançado) do Quadro Europeu Comum de Referência para as Línguas, encontrando-se, assim, no estádio imediatamente anterior ao estádio quase nativo, em que a agramaticalidade de inversão livre é naturalmente adquirida em inglês. Os aprendentes em cada nível de proficiência foram distribuídos uniformemente por dois grupos: o grupo experimental e o grupo de controlo.

Participaram ainda no estudo 26 falantes nativos de inglês, entre os 18 e os 52 anos. Estes eram estudantes universitários e, à data do estudo, viviam no Reino Unido. Apesar de terem aprendido, pelo menos, uma L2 durante o seu percurso escolar, não tinham proficiência avançada em qualquer L2. Os detalhes sobre o perfil sociolinguístico de cada grupo de participantes são apresentados na Tabela 2.

\begin{tabular}{|c|c|c|c|c|c|c|c|}
\hline \multirow[t]{2}{*}{ Grupo } & \multirow[t]{2}{*}{$N$} & \multicolumn{2}{|c|}{ Idade } & \multicolumn{2}{|c|}{$\begin{array}{c}\text { Idade de início de } \\
\text { exposição regular } \\
\text { ao inglês }\end{array}$} & \multicolumn{2}{|c|}{$\begin{array}{c}\text { Anos de } \\
\text { aprendizagem do } \\
\text { inglês }\end{array}$} \\
\hline & & Média & DP & Média & DP & Média & DP \\
\hline Grupo experimental & 10 & 20.3 & 2.9 & 7.5 & 1.1 & 9.9 & 1.3 \\
\hline Grupo de controlo & 10 & 19.2 & .9 & 7.4 & 1.9 & 11.6 & 2.2 \\
\hline Grupo de inglês L1 & 26 & 23.1 & 6.6 & - & - & - & - \\
\hline
\end{tabular}

Tabela 2: Perfil dos participantes

\subsection{Intervenção didática}

A intervenção didática foi feita através de duas unidades de ensino/aprendizagem a distância, que os participantes realizaram autonomamente em casa. As unidades continham evidência positiva (i.e., evidência do que é possível na L2), evidência negativa (i.e., evidência do que é impossível na L2), e atividades de prática sobre as propriedades alvo. A evidência positiva foi fornecida através de textos autênticos, frases de exemplo, e explicações sobre o uso de ordens SV em contextos de foco estreito e largo e sobre o tipo de verbos intransitivos compatíveis com inversão locativa em inglês. A evidência negativa foi fornecida através de feedback corretivo e de explicações e atividades sobre contrastes entre a L1 e a L2. Estas explicações e atividades visavam levar os aprendentes a tomarem consciência de que, contrariamente ao PE, o inglês não admite ordens ØVS nem permite inversão locativa com verbos informacionalmente pesados. 
Cada unidade centrou-se num fenómeno linguístico diferente. Porém, foi estruturada da mesma forma e teve a mesma duração (cerca de 75 a 80 minutos). As unidades seguiram a estrutura abaixo, que foi adaptada de Ellis (2002):

i. Ouvir / ler para compreender: o participante ouvia / lia um texto autêntico contendo múltiplas ocorrências das estruturas alvo com o objetivo de responder a perguntas de compreensão. Na unidade sobre inversão locativa, apenas foram utilizados textos escritos, pois esta estrutura é mais frequente no inglês escrito. Na unidade sobre ordens SV / VS, só foram usados textos orais, a fim de maximizar a exposição dos aprendentes à estratégia prosódica que o inglês usa na marcação de foco estreito no sujeito: a atribuição de acento marcado à posição de sujeito (e.g., JOHN arrived) (Reinhart, 2006). Como esta estratégia não é usada em PE, pode constituir evidência relevante para os aprendentes de que o inglês não se comporta como o PE em contextos de foco estreito.

ii. Ouvir / ler para notar (notice): o participante tinha de encontrar ocorrências de inversão locativa em textos escritos ou completar uma transcrição do áudio, da qual todas as respostas $\mathrm{SV}(\mathrm{O})$ a perguntas de foco estreito tinham sido suprimidas. O objetivo destas atividades era estimular o processo de noticing, que é visto por muitos investigadores como um pré-requisito para a aquisição de L2 (Schmidt, 1990, 2001).

iii. Descoberta e sistematização de regras: a partir dos textos (orais e escritos) usados nas etapas anteriores, uma série de perguntas conduzia o participante a descobrir as restrições às quais as propriedades alvo estão sujeitas em inglês e a contrastar a L2 e a L1. Depois de o participante responder a estas perguntas, aparecia uma explicação que sistematizava as regras que regulam o fenómeno linguístico em análise. Estas eram acompanhadas de exemplos.

iv. Prática controlada: o participante tinha de realizar três atividades de prática controlada. Estas envolviam: escolher, de entre várias opções, a tradução correta de frases em PE, avaliar a gramaticalidade de frases em inglês e, quando necessário, corrigi-las, e ordenar blocos de palavras para formar frases aceitáveis em inglês. Estas atividades, por um lado, permitiam ao participante pôr em prática o seu conhecimento explícito e, por outro, incentivavam-no a comparar a sua L1 com a L2 e a perceber as discrepâncias entre estes sistemas linguísticos.

v. Prática livre: cada unidade terminava com uma curta atividade de produção escrita (um poema em que tinham de usar, pelo menos, quatro frases com a ordem Loc VS e um diálogo em que tinha de usar, pelo menos, duas perguntas com who e duas com what happened e dar respostas completas às perguntas). O objetivo das atividades era levar os aprendentes a produzirem as estruturas alvo e, assim, ajudá-los a automatizar o conhecimento explícito aprendido.

vi. Perguntas de esclarecimento: o participante podia fazer perguntas (em inglês ou em PE) numa caixa de texto que aparecia no final da unidade. Estas perguntas eram respondidas pela investigadora por correio eletrónico.

vii. Autocorreção: Depois de enviar as suas respostas, o participante recebia automaticamente as soluções de todas as atividades e uma cópia das suas respostas, devendo autocorrigi-las e submetê-las novamente na plataforma. Tanto as primeiras respostas do participante como as respostas autocorrigidas foram registadas.

As taxas de acerto foram altas nas duas unidades de aprendizagem (antes da autocorreção: 91\% na unidade sobre inversão locativa e 95\% na unidade sobre ordens SV/VS; após autocorreção: 100\% em ambas as unidades). Análises estatísticas com recurso ao modelo mixed logit mostraram que as respostas dos participantes não diferiram significativamente entre as duas unidades de aprendizagem nem entre níveis de proficiência (todos os valores de $p \geq .12318$ ). Estes factos indicam que os participantes conseguiram acompanhar as unidades de aprendizagem com sucesso, independentemente do seu nível de proficiência e do tipo de fenómeno linguístico em estudo. 
Após concluir as duas unidades, o participante tinha de realizar um conjunto de atividades de revisão sobre os fenómenos linguísticos estudados. As atividades incluíam responder a perguntas de verdadeiro ou falso sobre as regras que tinham sido ensinadas, avaliar se uma frase é possível ou impossível em inglês, e escolher a ordem de palavras mais apropriada num determinado contexto linguístico. As atividades de revisão foram realizadas online no dia anterior ao primeiro pós-teste. Após submeterem as suas respostas, os participantes receberam feedback gerado por computador, em que se indicava, para cada pergunta, se a resposta estava correta e, no caso de não estar, qual seria a resposta certa e porquê.

\subsection{Testes}

Antes e após a intervenção didática, o conhecimento dos participantes foi avaliado através de dois testes de juízos de aceitabilidade rápidos (TJAR): um sobre inversão livre e outro sobre inversão locativa. As versões de cada teste usadas como pré-teste e como pós-testes diferiam apenas quanto à ordem dos itens. Todas incluíam 6 itens por condição e tantos distratores quanto itens experimentais. Nenhuma das frases usada nos testes foi incluída nas unidades de ensino/aprendizagem a distância. Cada um dos verbos incluídos nos itens experimentais foi usado apenas uma a duas vezes nas unidades sobre inversão locativa e inversão livre, que incluíam muitos verbos que não foram testados.

Em todos os TJAR, os participantes tinham de avaliar o mais depressa possível a aceitabilidade de uma frase que era apresentada palavra a palavra no centro do ecrã a um ritmo de $400 \mathrm{~ms}$ por palavra. ${ }^{5}$ A avaliação era feita numa escala de 1 a 5 , em que 1 correspondia a "totalmente inaceitável" e 5 a "totalmente aceitável". Antes de aparecer a frase a ser avaliada, era pedido aos participantes que lessem silenciosamente o contexto que a antecedia, o qual era apresentado como um único bloco de palavras, sem qualquer limite de tempo.

O TJAR sobre inversão livre cruzou as seguintes variáveis: ordem de palavras - SV vs. VS - e contexto discursivo - foco estreito $v s$. foco largo. Todos os itens experimentais incluíam um sujeito indefinido com três palavras e um verbo inacusativo compatível com os diferentes subtipos de inversão livre existentes em PE (arrive, come, enter, appear, die, be born). Os verbos encontravam-se flexionados no passado simples. A Tabela 3 apresenta exemplos de itens para cada uma das condições testadas.

\begin{tabular}{ccc}
$\begin{array}{c}\text { Tipo de ordem de } \\
\text { palavras }\end{array}$ & Tipo de contexto discursivo & Foco largo \\
\hline SV & Contexto: Why was the flag at half-mast yesterday? What & Contexto: Who died? \\
& happened? & A famous actor died. \\
VS & A war hero died. & \\
& Contexto: Why was the flag at half-mast yesterday? What & Contexto: Who died? \\
happened? & Died a rock singer. \\
\hline
\end{tabular}

Tabela 3: Itens de exemplo do teste sobre ordens SV/VS

O TJAR sobre inversão locativa testava se os aprendentes admitiam esta construção com verbos informacionalmente leves (nomeadamente, inacusativos de existência e aparecimento e inergativos redundantes) e verbos informacionalmente pesados (nomeadamente, inacusativos de mudança de estado e inergativos não redundantes). Neste teste, cada item experimental incluía um SP locativo definido com três palavras, um verbo no passado simples, um sujeito indefinido com 3 a 4 palavras, e um contexto prévio que

\footnotetext{
${ }^{5}$ Este é o ritmo tipicamente usado neste tipo de tarefas, uma vez que se assume que $400 \mathrm{~ms}$ é uma janela de tempo suficientemente curta para limitar a interferência de conhecimento explícito declarativo e suficientemente longa para os falantes completarem todos os processos de compreensão normais, como acesso lexical, integração sintática e interpretação semântica, e (cf. Bader \& Häussler, 2010; Hopp, 2007).
} 
forçava o sujeito a ser interpretado como foco e o SP a ser interpretado como tópico, sendo, assim, um contexto favorável a inversão locativa. A Tabela 4 apresenta itens de exemplo.

\begin{tabular}{|c|c|c|}
\hline \multicolumn{2}{|c|}{ Tipo de verbo } & Item de exemplo \\
\hline 冚 & $\begin{array}{l}\text { Inacusativos de } \\
\text { existência e } \\
\text { aparecimento }\end{array}$ & $\begin{array}{l}\text { Contexto: We slept in an abandoned house. In the morning, a sharp knock } \\
\text { on the door woke us up. Slowly the door opened and... } \\
\text { into the house came a bearded man. }\end{array}$ \\
\hline 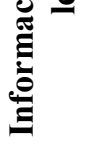 & $\begin{array}{l}\text { Inergativos } \\
\text { redundantes }\end{array}$ & $\begin{array}{l}\text { Contexto: 'Have you seen this?' Kate, the future Mrs Jones, proudly thrust } \\
\text { her left hand under our noses. } \\
\text { On her finger glittered an enormous diamond. }\end{array}$ \\
\hline 莺 & $\begin{array}{c}\text { Inacusativos de } \\
\text { mudança de estado }\end{array}$ & $\begin{array}{l}\text { Contexto: Another winter storm hit New York on Monday, causing traffic } \\
\text { jams in the streets of the city. Yesterday the weather conditions improved } \\
\text { and... } \\
\text { on the streets melted a lot of snow. }\end{array}$ \\
\hline 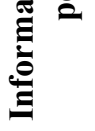 & $\begin{array}{c}\text { Inergativos não } \\
\text { redundantes }\end{array}$ & $\begin{array}{l}\text { Contexto: The enormous central library was in a state of decay. Some } \\
\text { bookcases were completely covered in dust and spider webs. } \\
\text { Near those bookcases sneezed many library users. }\end{array}$ \\
\hline
\end{tabular}

Tabela 4: Itens de exemplo da tarefa sobre inversão locativa

Foram usados TJAR no presente estudo por duas razões. A primeira é que tem sido mostrado que estes testes conseguem captar problemas em interfaces linguísticas que outros testes offline não conseguem detetar (e.g., Hopp, 2007; Teixeira, 2017, 2018). A segunda é que estudos psicométricos recentes validaram estes testes como medidas de conhecimento implícito (Ellis, 2005; Ellis et al., 2009) ou, pelo menos, de conhecimento explícito automatizado (Kim \& Nam, 2016; Suzuki \& DeKeyser, 2017), ou seja, conhecimento que é funcionalmente equivalente ao conhecimento implícito, embora envolva algum grau de consciência por parte do falante. Assim, este tipo de teste é um instrumento útil para se determinar se o ensino explícito tem efeitos positivos na aquisição de L2.

\subsection{Análise dos dados}

A análise estatística dos dados foi realizada usando modelos de efeitos mistos com efeitos aleatórios para participantes e itens. Nas análises dos dados relativos às ordens SV / VS, as variáveis modeladas como efeitos fixos foram as seguintes: "contexto discursivo", "ordem de palavras", "grupo", "teste", e "proficiência". Nas análises dos dados relativos à inversão locativa, os efeitos fixos foram as variáveis "tipo de verbo", "grupo", "teste", e "proficiência". Em todas as análises, os efeitos fixos foram codificados contrastivamente com os códigos .5 e -.5 para comparar dois níveis do mesmo efeito fixo (e.g., para proficiência, B2 = -.5 vs. C1 =.5). Seguindo Cunnings (2012) e Linck e Cunnings (2015), as análises incluíram interceções aleatórias para participantes e itens, declives aleatórios por participante para as variáveis intra-sujeitos e a sua interação, e declives aleatórios por item para a variável grupo (mas apenas nas análises inter-grupos). A análise estatística foi conduzida em R, usando a função lmer do pacote lme4. Dado que esta função apenas gera valores de $t$, usámos o valor de $t$ como medida de significância. Como é habitual na literatura (cf. Linck \& Cunnings, 2015), um efeito fixo foi considerado estatisticamente significativo sempre que o valor absoluto de $t$ é superior ou igual a 2.00. Sempre que o valor de $t$ era menor que 2.00, mas maior que 1.50 , o valor de $p$ foi estimado a partir da 
distribuição de $t$, para que se pudesse determinar se havia um efeito marginalmente significativo. O valor de $p$ foi estimado usando a seguinte fórmula de Baayen (2008: 248): $2 *$ (1 pt (abs (X), Y-Z)). Aqui, X é o valor de $t$, $\mathrm{Y}$ o número de observações, e $\mathrm{Z}$ o número de parâmetros de efeitos fixos. $\mathrm{O}$ valor de $p$ foi considerado marginalmente significativo nos casos em que era maior que 0.05 e menor que 1 .

\section{Resultados}

\subsection{Ordens SV / VS}

O pré-teste mostrou que, antes da intervenção didática, o grupo experimental e o grupo de controlo tinham um desempenho convergente com o dos falantes de inglês L1 relativamente às ordens SV (grupo experimental vs. monolingues: estimativa $=.000641, \mathrm{EP}=.198965, t=.01$; grupo de controlo $v s$. monolingues: estimativa $=.10897$, $\mathrm{EP}=.20431, t=.53$ ). Contudo, como a Figura 1 mostra, os dois grupos de aprendentes aceitavam ordens VS significativamente mais do que os falantes de inglês (grupo experimental $v$ s. monolingues: estimativa $=-1.6814, \mathrm{EP}$ $=.2531, t=-6.643$; grupo de controlo $v s$. monolingues: estimativa $=-1.3814, \mathrm{SE}=.2972, t=-4.648)$. Este padrão de comportamento foi encontrado nos dois contextos discursivos testados - foco estreito e foco largo ( $t \mathrm{~s} \leq-1.373$ para o fator contexto em todas as análises). Dentro do grupo de controlo e do grupo experimental, não foram encontradas diferenças significativas entre as respostas dos aprendentes no nível B2 e as dos aprendentes no nível $\mathrm{C} 1(t \mathrm{~s} \leq .678)$.

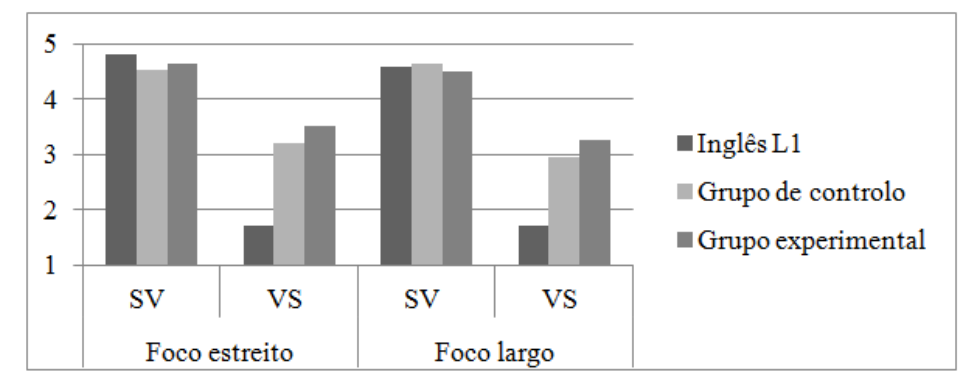

Figura 1: Média de aceitação das ordens SV e VS no pré-teste (escala 1-5)

Tal como ilustrado na Figura 2, o desempenho do grupo de controlo não melhorou com o tempo (pré-teste $v s$. pós-teste 1 : estimativa $=.03125, \mathrm{EP}=.22316, t=.140$; pré-teste $v s$. pós-teste 2 : estimativa $=.28125, \mathrm{EP}=$ $.19 .351, t=1.453)$. Já no grupo experimental, a aceitação de ordens VS diminuiu significativamente no primeiro pós-teste (estimativa $=-1.49306, \mathrm{EP}=.20399, t=-7.319$ ). Contudo, voltou a aumentar no segundo pós-teste em todos os contextos discursivos considerados (pós-teste $1 v s$ pós-teste 2 : efeito de teste - estimativa $=.7708$, $\mathrm{EP}=.3308, t=2.330$; fator contexto e interação teste-contexto $-t \mathrm{~s} \leq-1.434)$. Apesar deste aumento, o grupo experimental teve um desempenho melhor no segundo pós-teste do que no pré-teste em todos os contextos (préteste $v s$. pós-teste 2: efeito de teste - estimativa $=-.84722, \mathrm{EP}=.40543, t=-2.090$; fator contexto e interação teste-contexto $-t \mathrm{~s} \leq-1.005)$. 


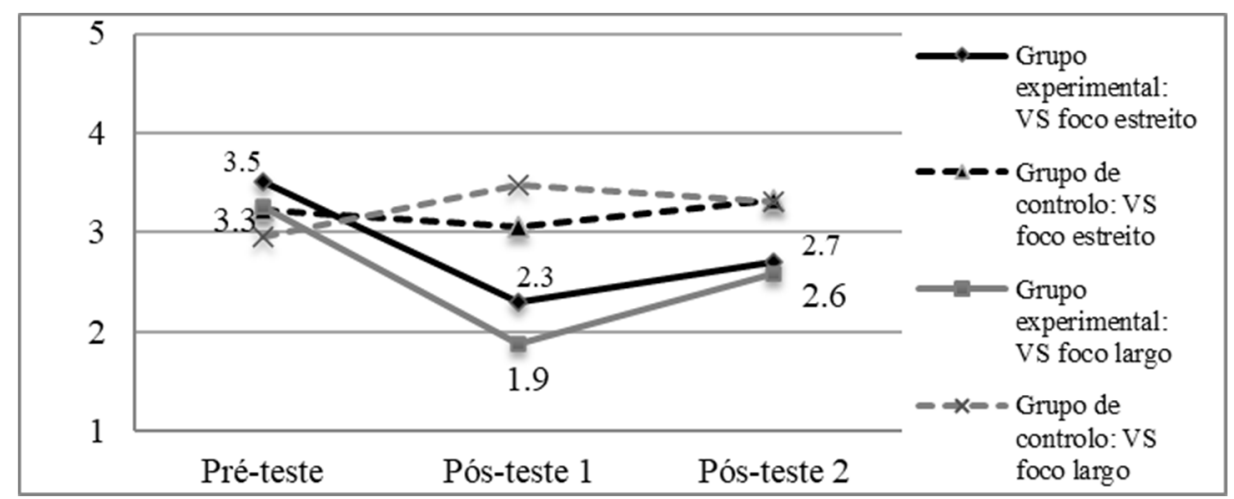

Figura 2: Média de aceitação da ordem VS nos três testes (escala 1-5)

A análise estatística das respostas do grupo experimental revelou uma interação significativa entre teste e proficiência na comparação entre o pré-teste e primeiro pós-teste (estimativa $=-2.01389, \mathrm{EP}=.40798, t=-4.936$ ) e marginalmente significativa na comparação entre o pré-teste e o segundo pós-teste (estimativa $=1.2083$, estimativa $=.6616, t=1.826[p=.06913009])$. É por isso relevante examinar os resultados deste grupo por nível de proficiência.

Como a Figura 3 mostra, no nível $\mathrm{C} 1$, a média de aceitação de ordens VS, que era de 3.6/3.5 antes da intervenção didática, diminuiu acentuadamente no primeiro pós-teste (estimativa $=2.50000, \mathrm{EP}=.24464, t=$ 10.219) e manteve-se relativamente baixa (2.3 / 2.1 ) no segundo pós-teste, apesar de um aumento marginal (pósteste $1 v s$. pós-teste 2 : estimativa $=1.3750, \mathrm{EP}=.7686, t=1.789[p=.07687049])$. Crucialmente, os resultados no último pós-teste foram significativamente melhores do que no pré-teste (estimativa $=1.12500 ; \mathrm{EP}=.27176, t=$ 4.140). Tendo em conta que, no grupo de controlo, os resultados dos aprendentes de nível C1 não se alteraram entre o pré-teste e o segundo pós-teste (estimativa $=.2708, \mathrm{EP}=.2740, t=.989$ ), podemos concluir, com segurança, que a intervenção didática foi a causa da melhoria observada no desempenho dos aprendentes de nível C1 que integravam o grupo experimental.

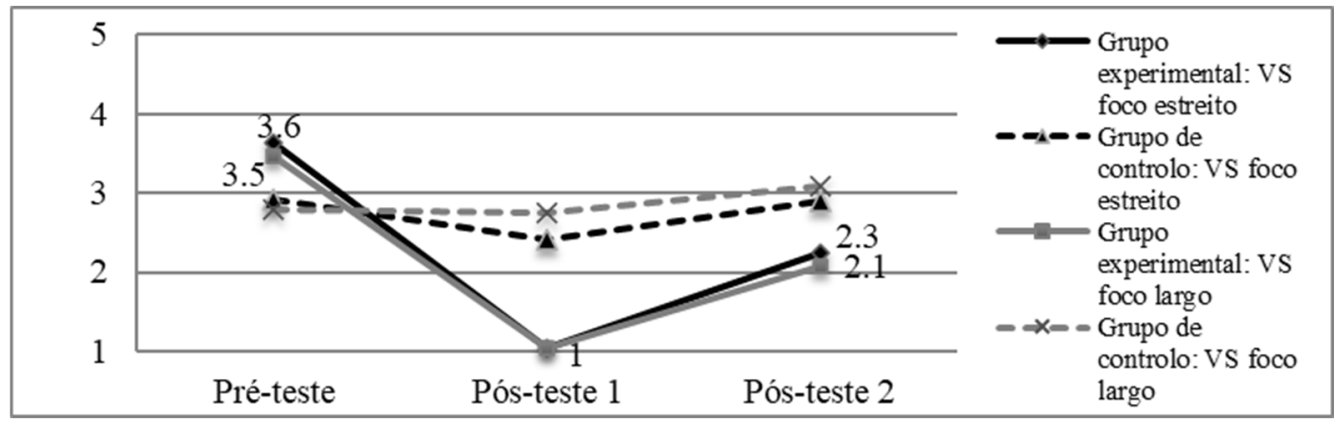

Figura 3: Média de aceitação da ordem VS no nível C1 nos três testes (escala 1-5)

Ao contrário do que aconteceu no nível $\mathrm{C}$ 1, no nível $\mathrm{B} 2$, o ensino explícito não teve efeitos nem no primeiro pós-teste (pré-teste $v s$. pós-teste 1: estimativa $=.6667, \mathrm{EP}=.4037, t=1.451$ ) nem no segundo pós-teste (pré-teste $v s$. pós-teste 2 : estimativa $=.3194, \mathrm{EP}=.3443, t=.928$ ), independentemente do tipo de contexto discursivo (todos os $t \mathrm{~s} \leq 1.651$ para o fator contexto). À semelhança dos aprendentes de nível B2 que fizeram parte do grupo 
experimental, os que integraram o grupo de controlo não progrediram entre o pré-teste e o pós-teste final (estimativa $=-.33333, \mathrm{EP}=.32350, t=-1.030)$, com se pode observar na Figura 4.

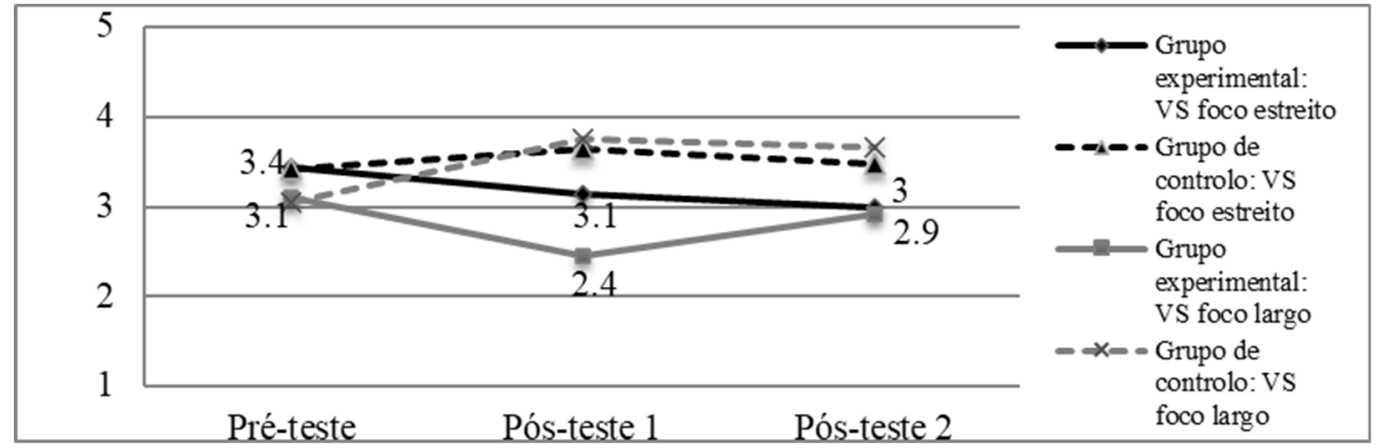

Figura 4: Média de aceitação da ordem VS no nível B2 nos três testes (escala 1-5)

\subsection{Inversão locativa}

Consideremos agora os resultados relativos à inversão locativa. Como ilustrado na Figura 5, no pré-teste, o grupo experimental e o de controlo aceitaram esta inversão com verbos informacionalmente leves tanto quanto os falantes nativos de inglês (grupo experimental vs. monolingues: estimativa $=.3038, \mathrm{EP}=.1955, t=1.55[p$ $=.1218755]$; grupo de controlo vs. monolingues: estimativa $=.1122, \mathrm{EP}=.1825, t=.91)$. O desempenho destes grupos, contudo, divergiu do dos falantes nativos de inglês no que diz respeito à aceitação de inversão locativa com verbos informacionalmente pesados. Tanto o grupo experimental como o de controlo aceitaram este tipo de inversão com verbos informacionalmente pesados significativamente mais do que os falantes nativos testados (grupo experimental $v s$. monolingues: estimativa $=-.5814, \mathrm{EP}=.2729, t=-2.131$; grupo de controlo $v s$. monolingues: estimativa $=-.5981, \mathrm{EP}=.3043, t=-1.965[p=.05005911])$. Dentro do grupo de controlo e do grupo experimental, não foram encontradas diferenças significativas a este respeito entre as respostas dos aprendentes no nível B2 e as dos aprendentes no nível $\mathrm{C} 1(t \mathrm{~s} \leq-.683)$. Todos sobreaceitaram inversão locativa.

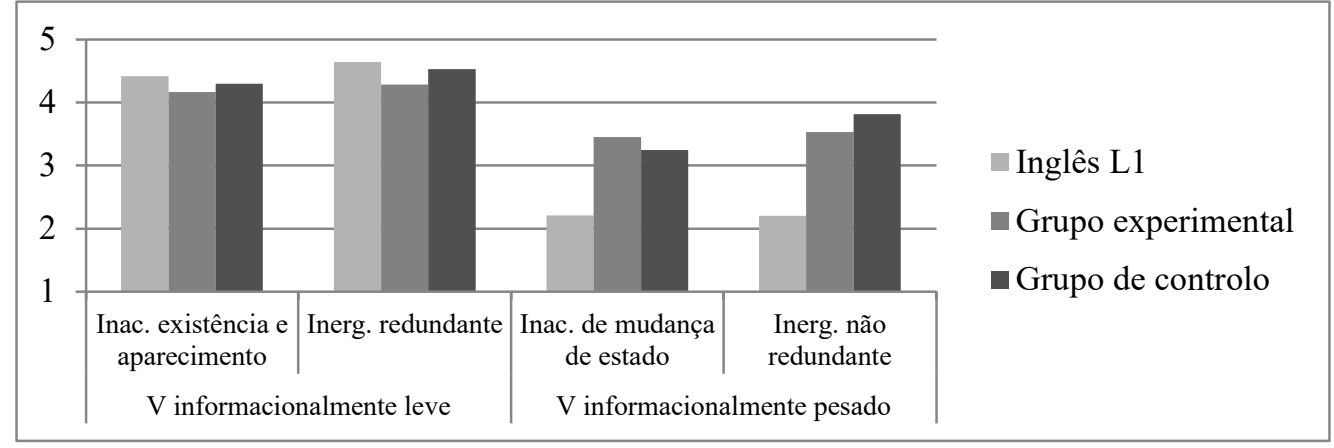

Figura 5: Média de aceitação de inversão locativa no pré-teste (escala 1-5)

O desempenho do grupo de controlo não melhorou ao longo do tempo. Como se pode observar na Figura 6, neste grupo, a média de aceitação de inversão locativa com verbos informacionalmente pesados aumentou marginalmente do pré-teste para o primeiro pós-teste $($ estimativa $=.3090, \mathrm{EP}=.1726, t=1.790[\mathrm{p}=.07473044])$ 
e, no segundo pós-teste, voltou a níveis idênticos aos exibidos no início do estudo (estimativa $=.3264, \mathrm{EP}=.2247$, $t=1.453[p=.1475465]$ ). Ao contrário do que aconteceu no grupo controlo, no grupo experimental, a média de aceitação de verbos informacionalmente pesados em inversão locativa baixou significativamente no primeiro pósteste (estimativa $=-.9653, \mathrm{EP}=.1815, t=-5.318$ ). No entanto, voltou a subir no segundo pós-teste (pós-teste $1 \mathrm{vs}$. pós-teste 2 : estimativa $=-.7361, \mathrm{EP}=.2678, t=-2.748)$. A análise comparativa dos resultados do grupo experimental no pré-teste e no segundo pós-teste revelou não existir qualquer efeito de teste, de tipo de verbo, ou de nível proficiência nem nenhuma interação significativa entre fatores (todos os $t \mathrm{~s} \leq .595$ ). Esta análise indica, assim, que, no segundo pós-teste, todo o grupo experimental, incluindo os aprendentes com nível $\mathrm{C} 1$, voltou a ter o mesmo padrão de comportamento linguístico exibido antes da intervenção didática.

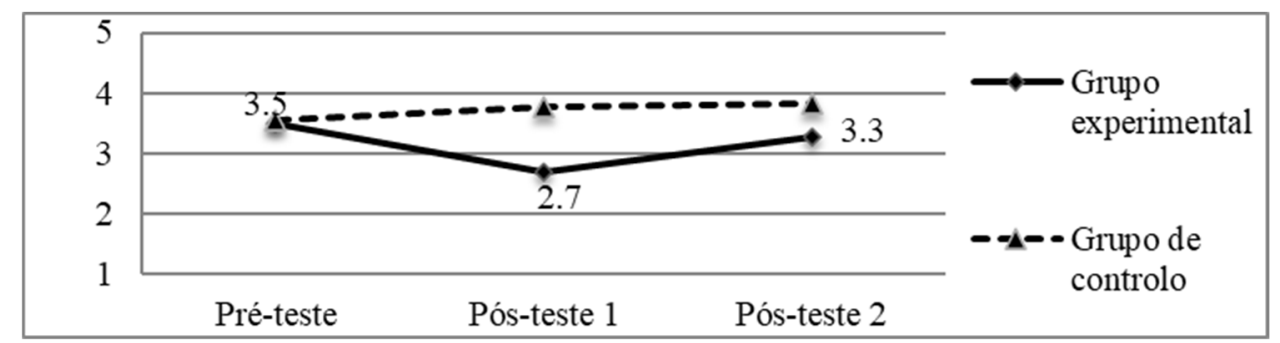

Figura 6: Média de aceitação de inversão locativa com verbos informacionalmente pesados nos três testes (escala 1-5)

O nível de proficiência, no entanto, teve um efeito significativo na comparação entre o pré-teste e o primeiro pós-teste (efeito de proficiência: estimativa $=-1.1458, \mathrm{EP}=.4691, t=-2.443$; interação teste-proficiência: estimativa $=-1.4861, \mathrm{SE}=.3630, \mathrm{t}=-4.094$ ), bem como na comparação entre o primeiro e o segundo pós-testes (efeito de proficiência: estimativa $=-1.1250, \mathrm{EP}=.4636, t=-2.427$; interação teste-proficiência: estimativa $=-1.5278, \mathrm{EP}$ $=.5357, t=-2.852$ ). Por este motivo, é importante examinar os resultados do grupo experimental por nível de proficiência.

Como a Figura 7 mostra, antes da intervenção didática, os aprendentes nos níveis C1 e B2 que integravam o grupo experimental apresentavam um comportamento semelhante quanto à aceitabilidade de inversão locativa com verbos informacionalmente pesados $(\mathrm{C} 1 v s . \mathrm{B} 2$ : estimativa $=-.40278, \mathrm{EP}=.58945, t=-.683)$. No entanto, nos testes que se realizaram após a intervenção, o desempenho dos aprendentes $\mathrm{C} 1$ e B2 foi significativamente diferente. No grupo C1, a aceitação de inversão com verbos informacionalmente pesados diminuiu consideravelmente do préteste para o primeiro pós-teste (estimativa $=-1.7083, \mathrm{EP}=.2777, t=-6.151$ ), mas aumentou no segundo pós-teste (estimativa $=-1.5000, \mathrm{EP}=.6133, t=-2.446$ ), atingindo um nível semelhante ao do pré-teste (pós-teste 2 vs. préteste: estimativa $=-.2083, \mathrm{EP}=.7649, t=-.272$ ). Em contraste, no grupo $\mathrm{B} 2$, as taxas de aceitação permaneceram praticamente inalteradas em todas as ocasiões de teste (pré-teste $v s$. pós-teste 1 : estimativa $=-.2222, \mathrm{EP}=.2579, t$ $=-.862$; pré-teste $v s$. pós-teste 2 : estimativa $=-.2500, \mathrm{EP}=.3813, t=-.656)$. 


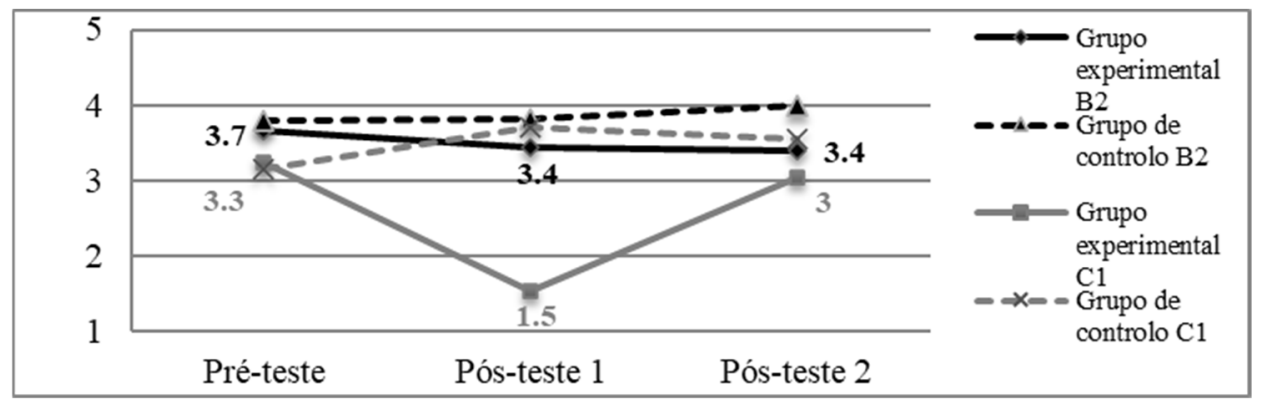

Figura 7: Média de aceitação de inversão locativa com verbos informacionalmente pesados nos três testes por nível de proficiência (escala 1-5)

Neste estudo, o impacto do ensino explícito no grupo experimental variou, assim, de acordo com o nível de proficiência e o tipo de propriedade alvo. No nível B2, o ensino explícito não teve efeitos nem a curto nem a médio prazo, independentemente do tipo de propriedade. No nível $\mathrm{C} 1$, em contraste, o ensino resultou em ganhos para todas as propriedades. No entanto, estes ganhos só se mantiveram a médio prazo no caso da inversão livre.

\section{Discussão}

Em conjunto, os resultados do presente estudo confirmam que o ensino explícito da gramática pode ajudar os aprendentes a ultrapassarem as suas dificuldades na L2 e indicam que o grau de eficácia deste ensino é influenciado por, pelo menos, dois fatores: o tipo de propriedade alvo e o estádio de aquisição em que o aprendente se encontra.

Em relação ao primeiro fator, os resultados mostram que, quando o alvo do ensino é uma propriedade que envolve a interface sintaxe-discurso como a incompatibilidade de verbos informacionalmente pesados com inversão locativa, o ensino explícito não desencadeia mudanças duradouras no desempenho dos aprendentes. Em contraste, quando o foco é uma propriedade estritamente sintática como a agramaticalidade de inversão livre em inglês, o ensino explícito pode ter efeitos duradouros. Tendo em conta que investigação recente em aquisição de L2 tem mostrado que, para os aprendentes portugueses de inglês, é mais fácil eliminar inversão livre do que eliminar a possibilidade de inversão locativa com verbos informacionalmente pesados (cf. secção 2.2), os resultados do presente estudo constituem evidência clara de que, contrariamente ao que tem sido proposto por alguns autores (e.g., de Graaff, 1997; Housen et al., 2005 ; Spada \& Tomita, 2010; e.o.), o ensino explícito é mais eficaz para as propriedades menos complexas do que para as mais complexas.

Como, ao longo das últimas duas décadas, tem sido demonstrado que, de uma maneira geral, as propriedades na interface sintaxe-discurso são mais difíceis de adquirir em L2 do que propriedades estritamente sintáticas, os resultados deste estudo podem ainda ser interpretados como fortes indícios de que a eficácia do ensino explícito pode depender da complexidade dos domínios linguísticos envolvidos na estrutura alvo. $\mathrm{O}$ ensino explícito parece ser mais eficaz quando tem como foco um domínio que causa problemas de desenvolvimento mas não permanentes em L2, como a sintaxe, do que quando tem como foco uma área vulnerável com opcionalidade permanente, como a interface sintaxe-discurso.

É importante lembrar que, neste estudo, o grupo experimental recebeu ensino explícito sobre inversão locativa por um período muito curto de tempo (cerca de 100 minutos). Por isso, o ensino explícito pode não ter produzido efeitos duradouros na interface sintaxe-discurso não por tal ser impossível, mas sim por a intervenção didática ter sido demasiado curta. Os resultados deste estudo, no entanto, sugerem que as propriedades na 
interface sintaxe-discurso serão, no mínimo, menos permeáveis a efeitos de ensino explícito do que as propriedades estritamente sintáticas.

Consideremos agora o segundo fator que modela a eficácia do ensino explícito no presente trabalho: o estádio de aquisição em que o aprendente está. Como descrito na secção 4, o ensino explícito sobre inversão locativa e inversão livre só resultou em ganhos para os aprendentes que se encontravam num estádio avançado. Estes resultados sugerem que, como proposto pela Hipótese de Ensinabilidade (cf. secção 1), o ensino explícito poderá apenas produzir mudanças no conhecimento dos aprendentes quando estes estão próximos do estádio de desenvolvimento ${ }^{6}$ em que a propriedade alvo é naturalmente adquirida. ${ }^{7}$ Recorde-se que a inversão livre é tipicamente eliminada das interlínguas dos aprendentes portugueses de inglês num estádio quase nativo, e a possibilidade de inversão locativa com verbos informacionalmente pesados nunca desaparece completamente (cf. secção 2.2). Por isso, o nível avançado é o mais próximo do estádio em que as propriedades alvo são adquiridas.

Embora seja claro que o ensino explícito resultou em ganhos para os aprendentes num nível avançado, não é evidente se afetou o seu conhecimento implícito. No caso da inversão livre, o facto de os efeitos do ensino explícito terem sido mantidos numa medida de conhecimento implícito mesmo cinco semanas após a intervenção didática sugere que esta intervenção desencadeou alterações no conhecimento implícito dos aprendentes. No caso da inversão locativa, por outro lado, o facto de os ganhos imediatos dos aprendentes terem sido perdidos cinco semanas depois indica que o ensino não afetou o seu conhecimento implícito. Provavelmente, só teve efeitos no conhecimento explícito.

Note-se que, embora os TJAR tenham sido validados como medidas de conhecimento implícito por vários estudos psicométricos (e.g., Ellis, 2005; Ellis et al., 2009), no presente trabalho, os aprendentes podem ter usado conhecimento explícito declarativo nos TJAR aplicados imediatamente após a intervenção didática. Previsivelmente, após esta intervenção, o conhecimento explícito aprendido estaria ainda "fresco" na memória declarativa dos participantes, o que lhes permitia aceder a este conhecimento e usá-lo de forma relativamente rápida e sem muito esforço. É improvável que o mesmo tenha acontecido no pós-teste aplicado cinco semanas depois da intervenção por dois motivos. O primeiro é que o conhecimento explícito, como outros factos declarativos, é facilmente esquecido. O segundo é que, mesmo que parte do que os participantes aprenderam ainda estivesse na sua memória declarativa no momento do segundo pós-teste, aceder e usar este conhecimento seria provavelmente muito mais demorado e exigiria mais recursos de atenção nesse momento. Por este motivo, os aprendentes dificilmente teriam tempo e recursos atencionais suficientes para aceder e usar conhecimento explícito declarativo consistentemente numa TJAR cinco semanas depois da intervenção. No entanto, para determinar com maior certeza se o ensino explícito sobre inversão livre desencadeou a restruturação do conhecimento implícito dos aprendentes, resultando em melhorias de longo prazo, seria necessário realizar um outro pós-teste, por exemplo, um ano após a intervenção didática. Isto será feito em investigação futura.

\footnotetext{
${ }^{6}$ Note-se que a Hipótese de Ensinabilidade de Pienemann $(1984,1989)$ foi originalmente formulada para dar conta de como o ensino explícito afeta as sequências fixas de estádios de desenvolvimento pelas quais os aprendentes passam no processo de aquisição de certas propriedades gramaticais, como ordens de palavras em alemão. Portanto, no âmbito desta hipótese, o termo "estádio" era originalmente usado no sentido de estádio na sequência de desenvolvimento de uma propriedade gramatical específica. Aqui usamos o termo "estádio" no sentido mais lato de estádio geral de desenvolvimento na L2.

${ }^{7}$ É importante sublinhar que, como regra, os aprendentes não necessitam de ter um domínio avançado da L2 para poderem retirar benefícios do ensino explícito da gramática. Há evidência na literatura de que este tipo de ensino pode desencadear melhorias até mesmo no desempenho de aprendentes com níveis baixos de proficiência (Gass, Svetics, \& Lemelin, 2003).
} 


\section{Implicações didáticas}

Os resultados do presente estudo podem lançar nova luz sobre algumas questões-chave que permanecem em aberto no domínio da didática de L2, nomeadamente: Vale a pena ensinar gramática explicitamente em L2? Se a gramática for ensinada, que fenómenos linguísticos devem ser ensinados? Quando? Como?

No que diz respeito à primeira questão, os resultados deste estudo sugerem que o ensino explícito da gramática deve ter um lugar na sala de aula de L2, porque este tipo de ensino pode melhorar o desempenho dos aprendentes na L2 e ajudá-los a adquirir mais cedo propriedades que só são adquiridas naturalmente em estádios muito tardios (ver, no entanto, Rothman, 2008, que apresenta um caso em que as regras ensinadas, por serem excessivamente simplificadas, não correspondem às regras que regulam a língua alvo e tornam-se, por isso, um entrave à aquisição). Este efeito positivo do ensino explícito verificou-se no caso da inversão livre. Com propriedades como a agramaticalidade de inversão livre em inglês, que só é naturalmente adquirida no nível quase nativo, o ensino explícito é não só benéfico mas também necessário, pois são poucos os aprendentes que conseguem alcançar o nível quase nativo (Sorace, 2003), o que significa que também serão poucos os que conseguirão adquirir esta propriedade de modo natural, sem beneficiarem de qualquer forma de ensino explícito.

Embora o ensino explícito da gramática seja potencialmente benéfico, não é eficaz em todas as circunstâncias. Os resultados deste estudo demonstram que existem dois fatores que moderam a eficácia do ensino e, consequentemente, precisam de ser levados em consideração pelos professores de L2: (i) o tipo de propriedade alvo e (ii) o estádio de aquisição em que os aprendentes estão. Em relação ao tipo de propriedade, os resultados da nossa investigação sugerem que os fenómenos que envolvem domínios que constituem uma área de opcionalidade persistente em L2 (e.g., a interface sintaxe-discurso) são menos permeáveis a efeitos de ensino explícito do que os que envolvem domínios mais facilmente adquiríveis (e.g., sintaxe). Por isso, o foco principal do ensino deve estar nos domínios ou interfaces linguísticas mais permeáveis a efeitos de ensino (e.g., sintaxe). Os professores só se devem concentrar nas áreas mais complexas para os aprendentes de L2 - e.g., a interface sintaxe-discurso - depois de tudo o resto ter sido trabalhado.

Em relação ao timing do ensino, os resultados deste estudo indicam que o ensino explícito só resulta em ganhos quando os aprendentes estão próximos do estádio de desenvolvimento em que a propriedade alvo é naturalmente adquirida. É, por isso, importante que os professores e os currículos tenham em conta a investigação em aquisição de L2 para decidir em que nível uma dada propriedade gramatical deve ser ensinada. Se se souber que uma propriedade $\mathrm{P}$ é tipicamente adquirida num nível $\mathrm{N}$ (e.g., quase nativo), então é aconselhável só se investir no ensino de $\mathrm{P}$ no nível imediatamente anterior a $\mathrm{N}$ (e.g., avançado), já que este é o momento em que é mais provável que o ensino explícito produza resultados duradouros. A dificuldade desta solução é que a investigação em aquisição de L2 é ainda pouco conhecida pelos especialistas em didática e pelos professores. É, assim, necessária maior articulação entre os domínios de aquisição e didática de L2 no futuro.

Foquemo-nos, por fim, na questão de como a gramática deve ser ensinada. Os resultados deste estudo vêm colocar em causa um princípio defendido pela maioria das teorias de ensino-aprendizagem de L2: o princípio de que a L1 deve ser eliminada das aulas de L2 (para uma visão panorâmica, ver Cook, 2010; Hall \& Cook, 2012). Os nossos resultados sugerem, contra esta visão e em linha com propostas recentes de alguns investigadores em aquisição de L2 (e.g., Cook, 2010; Horst, White, \& Bell, 2010; McManus \& Marsden, 2016), que a L1 pode e deve ter um papel relevante, pelo menos, no ensino-aprendizagem da gramática em L2. O facto de, neste estudo, o ensino explícito sobre contrastes entre L1 e L2 ter ajudado os aprendentes a eliminar as hipóteses incorretas que formularam sobre a L2 a partir da L1 constitui evidência clara de que, ao contrário do que é geralmente assumido, é útil comparar L1 e L2 no ensino-aprendizagem da gramática e despertar nos aprendentes o que Horst et al. (2010) chamam consciência interlinguística (crosslinguistic awareness). Há vários tipos de atividades que podem ser usados para convidar os aprendentes a fazerem comparações entre L1 e L2 e notarem as diferenças entre estes sistemas. Alguns exemplos incluem: corrigir amostras de produções de 
aprendentes com erros de transferência da L1; identificar erros em más traduções (e.g., traduções geradas por computador) e discutir as suas causas; ou traduzir frases da L1 para a L2 e vice-versa.

Evidentemente, o uso de atividades que envolvam a comparação entre L1 e L2 é mais fácil quando o grupo de aprendentes partilha a mesma L1 do que quando a diversidade de L1s é grande. No entanto, mesmo quando se trabalha com grupos multilingues, é possível realizar este tipo de atividades. Note-se que as línguas do mundo variam de forma restrita, havendo propriedades comuns a várias línguas. Por esta razão, muitas vezes, na aquisição de L2, falantes com L1 distintas têm problemas de transferência semelhantes. Por exemplo, não são só os falantes de PE que tendem a transferir a possibilidade de inversão livre da sua L1 para o inglês. Falantes de outras LSN como o grego, o espanhol e o italiano também parecem exibir o mesmo problema. Assim, quando se trabalha com turmas multilingues, geralmente, é possível juntar pequenos grupos de falantes de L1s que partilham uma dada propriedade e fornecer a cada grupo atividades sobre problemas na L2 relacionados com a influência dessa propriedade da L1.

\section{Conclusão}

A partir do presente estudo exploratório, podemos chegar a quatro conclusões sobre o ensino explícito da gramática em L2, que são relevantes para os domínios de aquisição e didática de L2. Primeiro, o ensino explícito pode desencadear mudanças relativamente duradouras nas interlínguas dos aprendentes, devendo, por isso, ser integrado nas aulas de L2. Segundo, a eficácia do ensino varia de acordo com estádio de aquisição em que o aprendente se encontra, sendo maior quando este está num estádio próximo daquele em que a propriedade alvo é adquirida naturalmente. Terceiro, a eficácia do ensino explícito varia em função da complexidade da propriedade a ser aprendida. As propriedades que envolvem domínios que a investigação generativa mostrou serem potenciais áreas de divergência permanente em L2, como a interface sintaxe-discurso, parecem ser menos permeáveis a efeitos de ensino explícito do que as propriedades que envolvem um domínio como a sintaxe, que não cria problemas de aquisição permanentes. Por fim, e tendo em conta as conclusões anteriores, é fundamental que os currículos, os professores e os autores de materiais didáticos tenham em consideração os resultados da investigação em aquisição de L2 para definirem que fenómenos linguísticos devem ser ensinados, quando, e como. Para que isto se possa tornar uma realidade, é necessário que, no futuro, passe a haver maior colaboração entre os domínios de aquisição e de didática de L2.

\section{Referências:}

Akakura, M. (2012) Evaluating the effectiveness of explicit instruction on implicit and explicit L2 knowledge. Language Teaching Research, 16(1), pp. 9-37.

Baayen, R. H. (2008) Analyzing linguistic data: A practical introduction to statistics using R. Cambridge: Cambridge University Press.

Bader, M., \& Häussler, J. (2010) Toward a model of grammaticality judgments. Journal of Linguistics, 46(2), pp. 273-330.

Bresnan, J. (1994) Locative inversion and the architecture of Universal Grammar. Language, 70(1), pp. $72-131$.

Chomsky, N. (1981) Lectures on government and binding. Dordrecht: Foris.

Cook, G. (2010) Translation in language teaching. Oxford: Oxford University Press.

Costa, J. (2004) Subject positions and interfaces. The case of European Portuguese. Berlin: Mouton de Gruyter. Culicover, P., \& Winkler, S. (2008) English focus inversion. Journal of Linguistics, 44(03), pp. 625-658.

Cunnings, I. (2012) An overview of mixed-effects statistical models for second language researchers. Second Language Research, 28(3), pp. 369-382. 
de Graaff, R. (1997) The experanto experiment: Effects of explicit instruction on second language acquisition. Studies in Second Language Acquisition, 19(2), pp. 249-276.

de Graaff, R., \& Housen, A. (2009) Investigating the effects and effectiveness of L2 instruction. In M. Long \& C. J. Doughty (Eds.), The handbook of language teaching (pp. 726-755). Chichester: Wiley-Blackwell.

DeKeyser, R. M. (1995) Learning second language grammar rules: An experiment with a miniature linguistic system. Studies in Second Language Acquisition, 17(3), pp. 379-410.

Ellis, R. (2002a) Does form-focused instruction affect the acquisition of implicit knowledge?: A review of the research. Studies in Second Language Acquisition, 24(2), pp. 223-236.

Ellis, R. (2002b) The place of grammar instruction in the second/foreign language curriculum. In E. Hinkel \& S. Fotos (Eds.), New perspectives on grammar teaching in second language classrooms (pp. 14-34). London: Routledge.

Ellis, R. (2005) Measuring implicit and explicit knowledge of a second language: A psychometric study. Studies in Second Language Acquisition, 27(2), pp. 141-172.

Ellis, R., Loewen, S., Elder, C., Philp, J., Reinders, H., \& Erlam, R. (2009) Implicit and explicit knowledge in second language learning, testing and teaching. Bristol: Multilingual Matters.

Gass, S., Svetics, I., \& Lemelin, S. (2003) Differential effects of attention. Language Learning, 53(3), pp. $497-$ 546.

Gil, K.-H., Marsden, H., \& Whong, M. (2013a) Can explicit grammar instruction serve as evidence for L2 grammar restructuring? In S. Stavrakaki, P. Konstantinopoulou, \& M. Lalioti (Eds.), Advances in language acquisition: Proceedings of GALA 2011 (pp. 328-336). Cambridge: Cambridge Scholars Publishing.

Gil, K.-H., Marsden, H., \& Whong, M. (2013b) Quantifiers: Form and meaning in second language development. In M. Whong, K.-H. Gil, \& H. Marsden (Eds.), Universal Grammar and the second language classroom (pp. 139-159). Dordrecht: Springer Netherlands.

Goo, J., Granena, G., Yilmaz, Y., \& Novella, M. (2015) Implicit and explicit instruction in L2 learning: Norris \& Ortega (2000) revisited and updated. In P. Rebuschat (Ed.), Implicit and explicit learning of languages (pp. 443-482). Amsterdam: John Benjamins Publishing.

Hall, G., \& Cook, G. (2012) Own-language use in language teaching and learning. Language Teaching, 45(3), pp. 271-308.

Holler, S., \& Hartmann, J. (2012) Locative inversion in English: Implications of a rating study In S. Featherston \& B. Stolterfoht (Eds.), Empirical approaches to linguistic theory: Studies in meaning and structure (pp. 241-265). Berlin: Mouton de Gruyter.

Hopp, H. (2007) Ultimate attainment at the interfaces in second language acquisition: Grammar and processing. (PhD thesis), University of Groningen, the Netherlands.

Horst, M., White, J., \& Bell, P. (2010). First and second language knowledge in the language classroom. International Journal of Bilingualism, 14(3), pp. 331-349.

Housen, A., Pierrard, M., \& Van Daele, S. (2005) Rule complexity and the effectiveness of explicit grammar instruction. In A. Housen \& M. Pierrard (Eds.), Investigations in instructed second language acquisition (pp. 207-241). Berlin: Mouton de Gruyter.

Ionin, T., Ko, H., \& Wexler, K. (2004) Article semantics in L2 acquisition: The role of specificity. Language Acquisition, 12(1), pp. 3-69.

Ionin, T., Montrul, S., \& Santos, H. (2011) An experimental investigation of the expression of genericity in English, Spanish and Brazilian Portuguese. Lingua, 121(5), pp. 963-985.

Kim, J.-e., \& Nam, H. (2016) Measures of implicit knowledge revisited: Processing modes, time pressure, and modality. Studies in Second Language Acquisition, 39(3), pp. 431-457.

Levin, B. (1993) English verb classes and alternations: A preliminary investigation. Chicago / London: The Chicago University Press. 
Levin, B., \& Rappaport Hovav, M. (1995) Unaccusativity at the syntax-lexical semantics interface. Cambridge, MA: MIT Press.

Linck, J., \& Cunnings, I. (2015) The utility and application of mixed-effects models in second language research. Language Learning, 65, pp. 185-207.

Lobo, M., \& Martins, A. M. (2017) Subjects. In A. Dufter \& E. Stark (Eds.), Manual of Romance morphosyntax and syntax (pp. 27-88). Berlin/Boston: De Gruyter.

Lopez, E. (2019) Teaching the English article system: Definiteness and specificity in linguistically-informed instruction. Language Teaching Research, 23(2), pp. 200-217. doi:10.1177/1362168817739649

Lozano, C., \& Mendikoetxea, A. (2010) Interface conditions on postverbal subjects: A corpus study of L2 English. Bilingualism: Language and Cognition, 13(04), pp. 475-497.

Macaro, E., \& Masterman, L. (2006) Does intensive explicit grammar instruction make all the difference? Language Teaching Research, 10(3), pp. 297-327.

Mackey, A., \& Philp, J. (1998) Conversational interaction and second language development: Recasts, responses, and red herrings? The Modern Language Journal, 82(3), pp. 338-356.

McManus, K., \& Marsden, E. (2016) L1 explicit instruction can improve L2 online and offline performance. Studies in Second Language Acquisition, 39(3), pp. 459-492.

Norris, J. M., \& Ortega, L. (2000) Effectiveness of L2 instruction: A research synthesis and quantitative metaanalysis. Language Learning, 50(3), pp. 417-528.

Pereira, C. (1998) Inversão locativa em português. (MA dissertation), Universidade do Porto, Portugal.

Pienemann, M. (1984) Psychological constraints on the teachability of languages. Studies in Second Language Acquisition, 6(2), pp. 186-214.

Pienemann, M. (1989) Is language teachable? Psycholinguistic experiments and hypotheses. Applied Linguistics, 10(1), pp. 52-79.

Pienemann, M. (Ed.) (2005) Cross-linguistic aspects of Processability Theory. Amsterdam: John Benjamins.

Pinto, M. (1997) Licensing and interpretation of inverted subjects in Italian. (PhD thesis), Utrechts Instituut voor Linguistiek.

Prentza, A., \& Tsimpli, I. (2013) The interpretability of features in second language acquisition: Evidence from null and postverbal subjects in L2 English. Journal of Greek Linguistics, 13, pp. 323-365.

Reinhart, T. (2006) Interface strategies: Optimal and costly computations. Cambridge, MA: MIT Press.

Robinson, P. (1996) Learning simple and complex second language rules under implicit, incidental, rule-search, and instructed conditions. Studies in Second Language Acquisition, 18(1), pp. 27-67.

Rothman, J. (2008) Aspect selection in adult L2 Spanish and the competing systems hypothesis: when pedagogical and linguistic rules conflict. Languages in Contrast, 8 (1), pp. 74-106.

Schmidt, R. (1990) The role of consciousness in second language learning. Applied Linguistics, 11, pp. 129158.

Schmidt, R. (2001) Attention. In P. Robinson (Ed.), Cognition and second language instruction (pp. 3-32). Cambridge / New York: Cambridge University Press.

Sheehan, M. (2010) 'Free' inversion in Romance and the null subject parameter. In T. Biberauer, A. Holmberg, I. Roberts, \& M. Sheehan (Eds.), Parametric variation: Null subjects in minimalist theory (pp. 231-262). Cambridge: Cambridge University Press.

Slabakova, R. (2002) The compounding parameter in second language acquisition. Studies in Second Language Acquisition, 24(4), pp. 507-540.

Slabakova, R. (2008) Meaning in the second language. Berlin: Mouton de Gruyter.

Sorace, A. (2003) Near-nativeness. In C. J. Doughty \& M. Long (Eds.), The handbook of second language acquisition (pp. 130-151). Oxford: Blackwell. 
Sorace, A. (2011) Pinning down the concept of 'interface' in bilingualism. Linguistic Approaches to Bilingualism, 1, pp. 1-33.

Sorace, A. (2016) Referring expressions and executive functions in bilingualism. Linguistic Approaches to Bilingualism, 6(5), pp. 669-684.

Sorace, A., \& Filiaci, F. (2006) Anaphora resolution in near-native speakers of Italian. Second Language Research, 22(3), pp. 339-368.

Spada, N., \& Lightbown, P. (1999) Instruction, first language influence, and developmental readiness in second language acquisition. The Modern Language Journal, 83(1), pp. 1-22.

Spada, N., \& Tomita, Y. (2010) Interactions between type of instruction and type of language feature: A metaanalysis. Language Learning, 60(2), pp. 263-308.

Suzuki, Y., \& DeKeyser, R. M. (2017) The interface of explicit and implicit knowledge in a second language: Insights from individual differences in cognitive aptitudes. Language Learning, 67(4), pp. 747-790.

Teixeira, J. (2016) Locative inversion and stage topics: A cross-linguistic study. Discours, 19, pp. 5-28.

Teixeira, J. (2017) Será a interface sintaxe-discurso necessariamente um locus de opcionalidade em L2? O caso da inversão locativa em inglês L2. Revista da Associação Portuguesa de Linguística, 3, pp. 347-386.

Teixeira, J. (2018) L2 acquisition at the interfaces: Subject-verb inversion in L2 English and its pedagogical implications. (PhD thesis), Universidade Nova de Lisboa, Portugal.

Teixeira, J. (2020) Gradient optionality in L2 acquisition at the syntax-discourse interface: Evidence from inversion in advanced and near-native English. Lingua, 245, 102947. doi: https://doi.org/10.1016/j.lingua.2020.102947

Umeda, M., Snape, N., Yusa, N., \& Wiltshier, J. (2019) The long-term effect of explicit instruction on learners' knowledge on English articles. Language Teaching Research, 23(2), pp. 179-199.

University of Cambridge Local Examination Syndicate, \& Oxford University. (2001) Quick placement test. Oxford: Oxford University Press.

Ward, G., Birner, B., \& Huddleston, R. (2002) Information packaging. In R. Huddleston \& G. K. Pullum (Eds.), The Cambridge grammar of the English language (pp. 1363-1447). Cambridge: Cambridge University Press.

White, L. (1991) Adverb placement in second language acquisition: Some effects of positive and negative evidence in the classroom. Second Language Research, 7(2), pp. 133-161.

Whong, M., Gil, K.-H., \& Marsden, H. (2014) Beyond paradigm: The 'what' and the 'how' of classroom research. Second Language Research, 30(4), pp. 551-568. 